\title{
Teaching Green Chemistry Principles to Undergraduate Students
}

\author{
By Mariya Rozov* \\ Tyler K. Brescia ${ }^{\dagger}$ \\ Lyanne Valdez \\ Rita K. Upmacis ${ }^{+}$
}

The environment is affected by the actions of mankind in multitudinous ways, many of which are detrimental, giving rise to pollution and toxic waste, ultimately making our planet less inhabitable. While remediation and new regulations help to prevent pollution and toxic waste, there is also a need to change the behavior of future generations of consumers and producers of new products. Future chemists and innovators are charged with the responsibility of developing new chemical processes and products that not only meet the needs of our growing population (in terms of energy, clean water and food), but also protect human health and the environment. Green Chemistry is a revolution in the design of molecules that provides new opportunities for economic development while considering the impact on health and the environment. Green Chemistry utilizes a set of guiding principles, originally provided by Anastas and Warner (Green Chemistry: Theory and Practice, 1998), aimed at decreasing/removing the use/generation of hazardous substances in the design, manufacture and application of products. To help improve the creative and innovative thinking behind Green Chemistry, it is important to expose chemistry students to these principles at the undergraduate level. While suitable Green Chemistry experiments are known, successful implementation requires running test trials and performing additional basic research. We have embarked upon the testing and further design of experiments for implementation into an undergraduate laboratory course and report our results in this endeavor.

\section{Introduction}

The most widely accepted definition of Green Chemistry (which is closely linked to Sustainable Chemistry) is 'the design, development and implementation of chemical processes and products to reduce or eliminate substances hazardous to human health and the environment' (Anastas and Warner 1998). A key difference between Environmental Chemistry and Green Chemistry is that while Environmental Chemistry seeks to understand the chemistry of the natural environment and substances that lead to pollution, Green Chemistry seeks to reduce and prevent pollution at its foundation. There are many global challenges that face mankind, which include promoting

\footnotetext{
*Undergraduate Student, Pace University, USA.

†Undergraduate Student, Pace University, USA.

*Undergraduate Student, Pace University, USA.

${ }^{+}$Associate Professor, Pace University, USA.
} 
sustainable development (e.g. meeting the needs of a growing population for food, clean water and energy without adversely affecting public health) while reducing global environmental risks (e.g. diminishing human behaviors that contribute to climate change) (Reid et al. 2010). Chemistry plays a role in all of these concerns and, moreover, Green Chemistry provides the opportunity to innovate. It is, therefore, important to expose undergraduate students to Green Chemistry with the goal of (i) imparting some of the successful approaches implemented to date and (ii) highlighting the impact that students can have in their future careers as innovators by using the fundamentals of chemistry to address global concerns.

A standard of 12 guiding principles was first developed by Anastas and Warner in 1998, and range from using reactions that use all atoms economically to performing inherently safer chemistry (Anastas and Warner 1998). By themselves, these principles are not new, but grouping them together this way was revolutionary and provided the foundation of Green Chemistry (Poliakoff and Anastas 2001). The 12 guiding Green Chemistry principles were later expanded to include 12 Green Engineering principles in order to address a number of concepts relevant to the impact on the environment, such as product life cycle and the use of renewable feedstocks (Anastas and Zimmerman 2003). More recently, a mnemonic "IMPROVEMENTS PRODUCTIVELY" was devised that can be used to manage all the principles and also aid discussion of Green processes (Figure 1) (Tang et al. 2008).

While suitable experiments for a Green Chemistry laboratory course are known (Doxsee and Hutchison 2004; ACS 2011), it is important to conduct test trials to ensure their successful implementation. Herein, we report the results from our testing and development of three different experiments for inclusion in a Green Chemistry Laboratory course aimed at undergraduate students majoring in Science, which include:

1. Aspirin synthesis using microwave technology (Montes et al. 2006; ACS 2011; Jones 2011).

2. Biodiesel fuel synthesis from oils used in the food industry (Thompson 2008).

3. Plastics and the synthesis of biodegradable polymers (Robert and Aubrecht 2008). 
Figure 1. The Green Engineering and Chemistry Principles are given by the mnemonic "IMPROVEMENTS PRODUCTIVELY". Taken from Tang SY, Bourne RA, Poliakoff M and Smith RL (2008). Green Chem. 10:268-269

\begin{tabular}{|ll|}
\hline I & - Inherently non-hazardous and safe \\
M & - Minim ize m aterial diversity \\
P & - Prevention instead of treatm ent \\
R & - Renewable m aterial and energy inputs \\
O & - Output-led design \\
V & - Very simple \\
E & - Efficient use of m ass, energy, space \& time \\
M & - Meet the need \\
E & - Easy to separate by design \\
N & - Networks for ex change of local m ass \& energy \\
T & - Test the life cycle of the design \\
S & - Sustainability throughout product life cycle \\
& \\
P & - Prevent wastes \\
R & - Renewable m aterials \\
O & - Omit derivatization steps \\
D & - Degradable chemical products \\
U & - Use safe synthetic m ethods \\
C & - Catalytic reagents \\
T & - Temperature, Pressure am bient \\
I & - In-process m onitoring \\
V & - very few auxiliary processes \\
E & - E-factor, m aximize feed in product \\
L & - Low toxicity of chemical products \\
Y & - Yes, it's safe \\
& \\
& \\
\hline
\end{tabular}

\section{Results and Discussion}

\section{Aspirin Synthesis using Microwave Technology}

Aspirin (acetylsalicylic acid) can be prepared from the reaction of salicylic acid and acetic anhydride (Figure 2a) (Montes et al. 2006; ACS 2011; Jones 2011). Aspirin was prepared by three different methods involving: (i) conventional synthesis (hot-water bath; $10 \mathrm{~min}$ ) requiring the addition of concentrated sulfuric acid $\left(\mathrm{H}_{2} \mathrm{SO}_{4} ; 3\right.$ drops) as a catalyst, (ii) a kitchen microwave oven $(1100 \mathrm{~W} ; 4 \mathrm{~min}$ at $80 \%$ power), and (iii) an industrial microwave synthesis unit (CEM DISCOVER microwave; $15 \mathrm{~min}$ at $200 \mathrm{~W}$ power; $1 \mathrm{~min}$ ramp time; $150{ }^{\circ} \mathrm{C} ; 200 \mathrm{psi}$ ) (Figure $2 \mathrm{~b}$ ). In each case, acetic anhydride $(3 \mathrm{~mL})$ was added to salicylic acid $(2.1 \mathrm{~g})$. In contrast to conventional synthesis, microwave synthesis of aspirin does not require the addition of concentrated $\mathrm{H}_{2} \mathrm{SO}_{4}$. After heating, scratching the walls of the vessel with a glass rod encouraged crystals to form. The crude product was isolated following the addition of ice water and then recrystallized from ethanol. The starting materials, together with the crude and recrystallized 
aspirin were analyzed by attenuated total reflectance infra-red (ATR-IR) spectroscopy (Nicolet 6700 FT-IR).

Figure 2. Aspirin Synthesis. The reaction of salicylic acid and acetic anhydride yielding acetylsalicylic acid (aspirin) and acetic acid (a) can be prepared using a CEM DISCOVER industrial microwave (b)

(a)

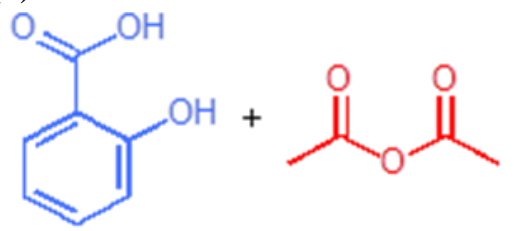

Salicylic Acid

Acetic Anhydride

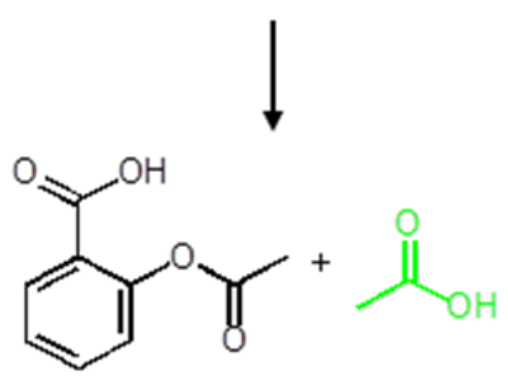

Acetylsalicylic Acid (b)

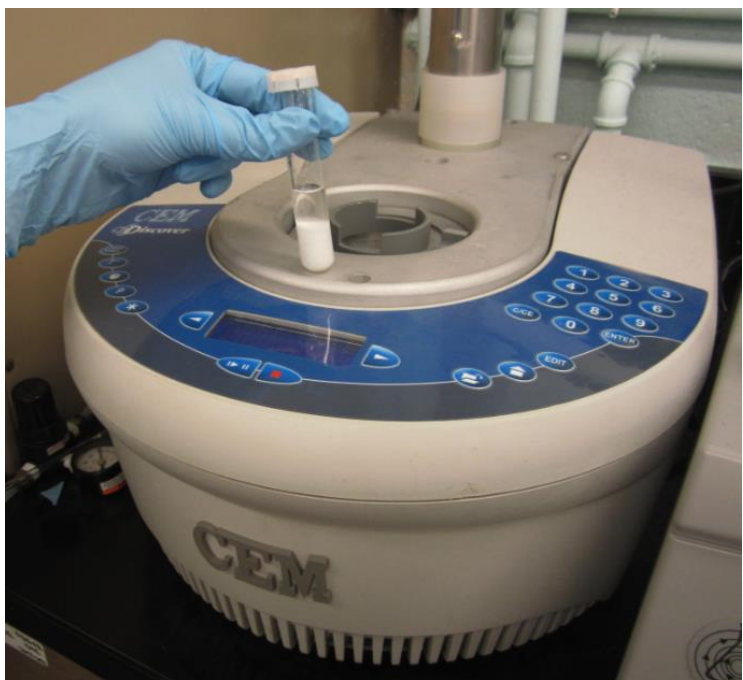

The conventional synthesis of aspirin requires heating the reactants in a flask in a traditional manner (i.e. the flask is placed in a beaker of hot water on a hot plate). Energy is required first to heat the hot plate so that the water in the beaker can be warmed, and only then can heat be transferred to the reactants in the flask. Energy transfer is thus uneven, inefficient and not direct. However, the use of microwave technology allows direct energy transfer and activation without the need of adding concentrated $\mathrm{H}_{2} \mathrm{SO}_{4}$, and can, therefore, be considered a "Green" technique (ACS 2011).

An industrial microwave has certain benefits compared to a kitchen microwave. For instance, although a kitchen microwave may operate with more power than an industrial microwave, much of the energy is wasted due to the size of the cavity being larger. Furthermore, hot spots may be created in a kitchen microwave due to high centers of electromagnetic intensity; therefore, to prevent an unwanted hazard, it is important to allow the sample time to cool before removal. In this regard, previous studies have pointed out that it is prudent to place a beaker of water (or vermiculite) in the cavity to absorb the extra energy and prevent overheating when using a kitchen microwave (CEM 2011). In contrast, an industrial microwave provides greater reproducibility due to homogeneous energy distribution in the cavity and greater control over power and temperature. Air is circulated through the sample cavity, thereby more efficiently cooling the sample before removal and, thus, increasing the safety of the experiment. 
Figure 3. Aspirin Synthesis. A comparison of the ATR-IR spectra of (a) the starting materials and pure products, and the crude and recrystallized aspirin products obtained by (b) conventional, (c) kitchen microwave and (d) industrial microwave syntheses

(a) Starting Materials and Products
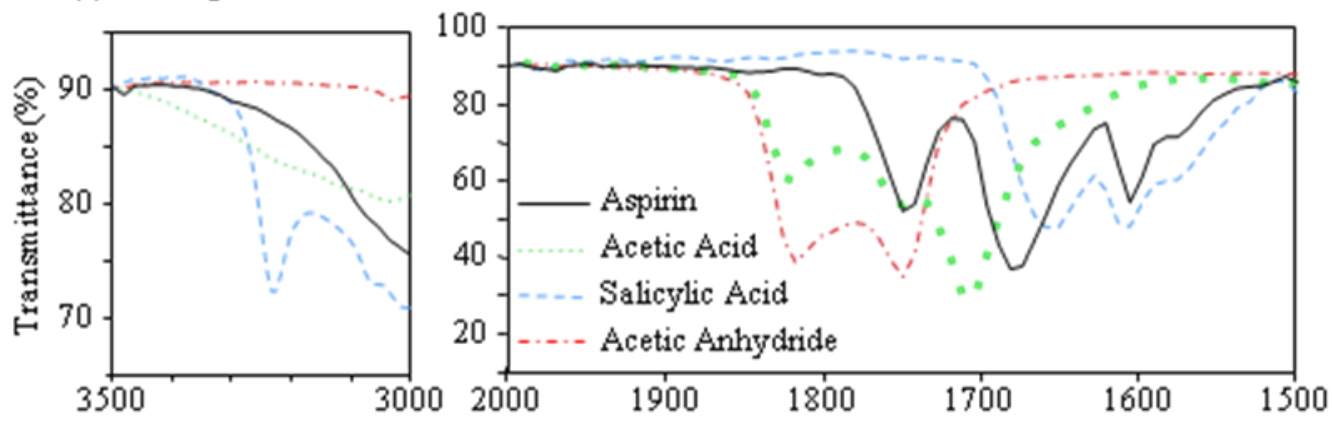

(b) Conventiona1Synthesis of Aspirin
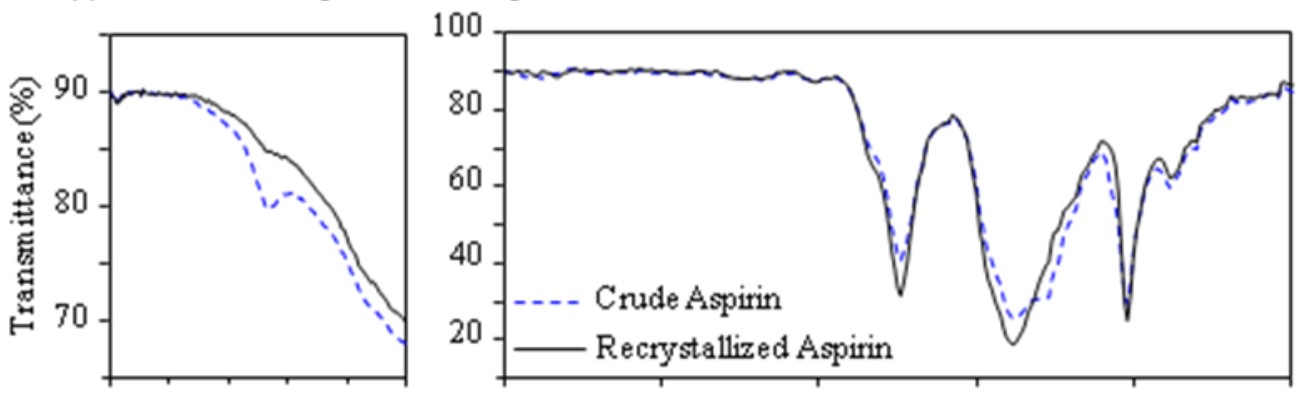

(c) Kitchen Microwave Synthesis of Aspirin
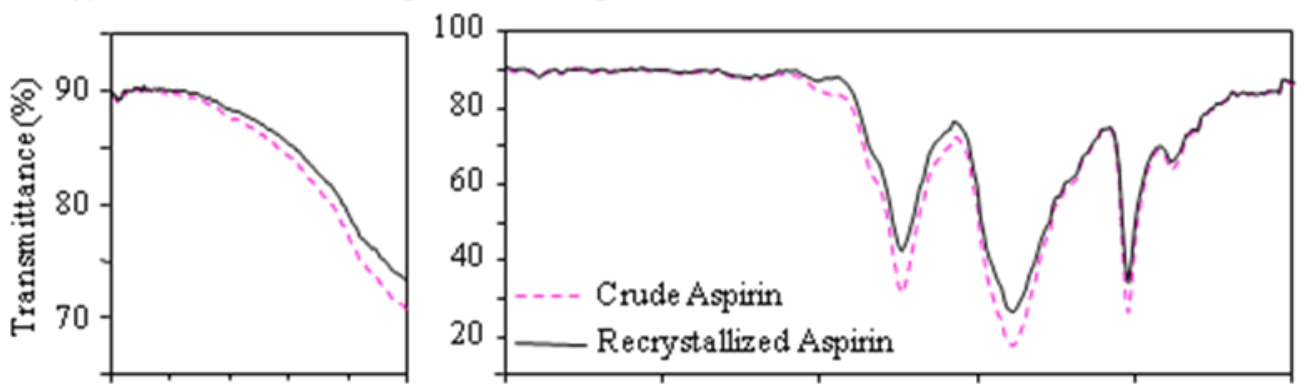

(d) IndustrialMicrowave Synthesis of Aspirin
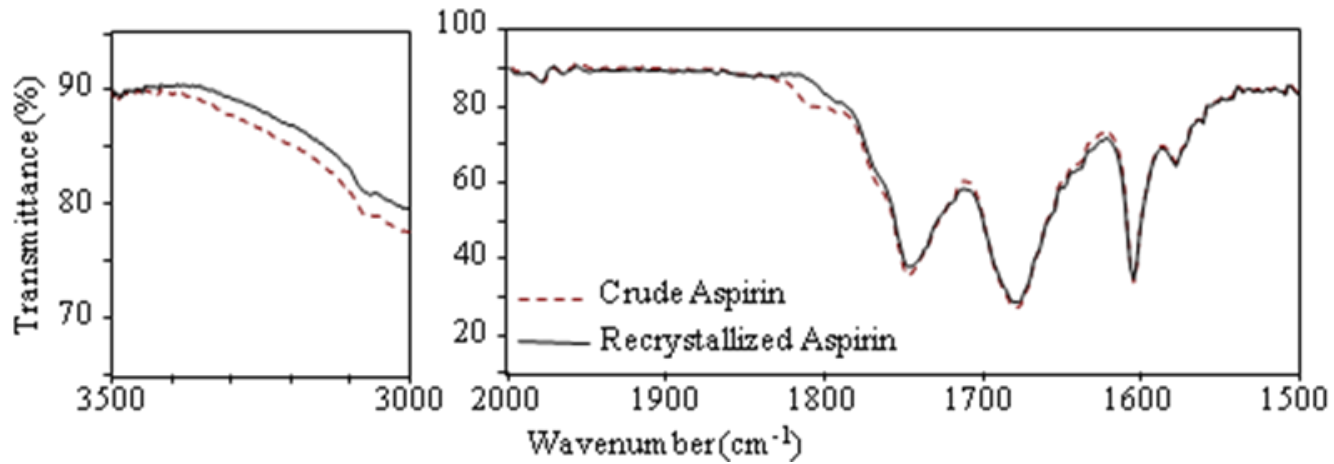
Representative infra-red (IR) spectra are provided (Figure 3a-d). The top panel shows a comparison of the IR spectra of the starting materials (acetic anhydride and salicylic acid) and the products (acetic acid and aspirin). In our hands, the conventional synthesis resulted in a crude product that showed evidence of the presence of starting material (i.e. $v_{\mathrm{OH}}$ at $3232 \mathrm{~cm}^{-1}$ corresponding to the $\mathrm{O}-\mathrm{H}$ stretch of the hydroxyl moiety attached to the benzene ring of salicylic acid). This signal, however, disappeared upon recrystallization. An inspection of the crude and recrystallized products from both the kitchen microwave and industrial microwave syntheses revealed that the products were similar, with no detectable evidence of unreacted starting materials. Thus, microwave synthesis (kitchen or industrial microwave) is fast and efficient, and leads to a purer crude product, even without the addition of concentrated acid. The Green principles featured in this experiment are: (i) energy efficiency, (ii) safer chemicals and reaction media, and (iii) less hazardous chemical synthesis.

\section{Biodiesel Fuel Synthesis}

Biodiesel oils are alternative fuels that can be synthesized from animal fats or waste cooking oils (Thompson 2008). Biodiesel fuels can be burned to provide heat or can be used to power diesel engines in e.g. buses, cars, trains and aircraft (Rothamer and Donohue 2013). However, in order to convert vegetable oil or animal fat into a viable source of fuel, it is necessary to lower the flash point, such that it is more combustible and burns more readily. In general, the flashpoints of pure organic liquids are related to the number of carbon atoms in the compound, and increase in a relatively linear fashion (Figure 4a) (Catoire and Naudet 2004). For instance, the flashpoints of alkanes containing $1-20$ carbons are in the range of $-188^{\circ} \mathrm{C}(85 \mathrm{~K})$ for methane $\left(\mathrm{CH}_{4}\right)$ to $169{ }^{\circ} \mathrm{C}(442 \mathrm{~K})$ for eicosane $\left(\mathrm{C}_{20} \mathrm{H}_{42}\right)$. Diesel (containing e.g. $8-21$ carbon atoms) is derived from petrochemical fuel stock and has a flashpoint just below $100{ }^{\circ} \mathrm{C}$.

Vegetable oils are triglycerides and can contain $>50$ carbons, such that they have high flashpoints $\left(>300{ }^{\circ} \mathrm{C}\right.$ ). The flashpoint may, however, be lowered (to ca. $122{ }^{\circ} \mathrm{C}$ ) by transesterification to form glycerol and smaller hydrocarbon fragments (Figure 4b) (Pinzi et al. 2011).

The conversion entails addition of vegetable oil $(100 \mathrm{~mL})$, that has been heated to $\sim 60^{\circ} \mathrm{C}$, to a solution of sodium methoxide, prepared by adding sodium hydroxide $(0.35 \mathrm{~g})$ to methanol $(20 \mathrm{~mL})$ with vigorous stirring (Thompson 2008). The contents were transferred to a separatory funnel and allowed to separate into two layers (the top layer contains the biodiesel fuel; the bottom layer contains glycerol). FT-IR spectroscopy was used to characterize the different layers. The top layer contains the biodiesel fuel and the bottom layer contains glycerol. The bottom layer shows a peak at $\sim 3200$ $\mathrm{cm}^{-1}$, which is characteristic of the $-\mathrm{OH}$ group of glycerol. A spectrum of pure glycerol highlights this feature (Figure 4c). A comparison of the top layer with the starting material reveals that spectroscopically they are similar in the 2500 
$-4000 \mathrm{~cm}^{-1}$ region. However, it is apparent that the biodiesel fuel burns more brightly than the starting material (Figure 4d).

Figure 4. Biodiesel Synthesis. (a) Flashpoints of alkanes (1 - 20 carbons) compared to different fuels. (b) Transesterification of vegetable oil involving methanol/sodium hydroxide. (c) IR spectra of corn oil, the top and bottom layers from a separatory funnel, and pure glycerol (for comparison). (d) Biodiesel fuel burns more brightly than corn oil
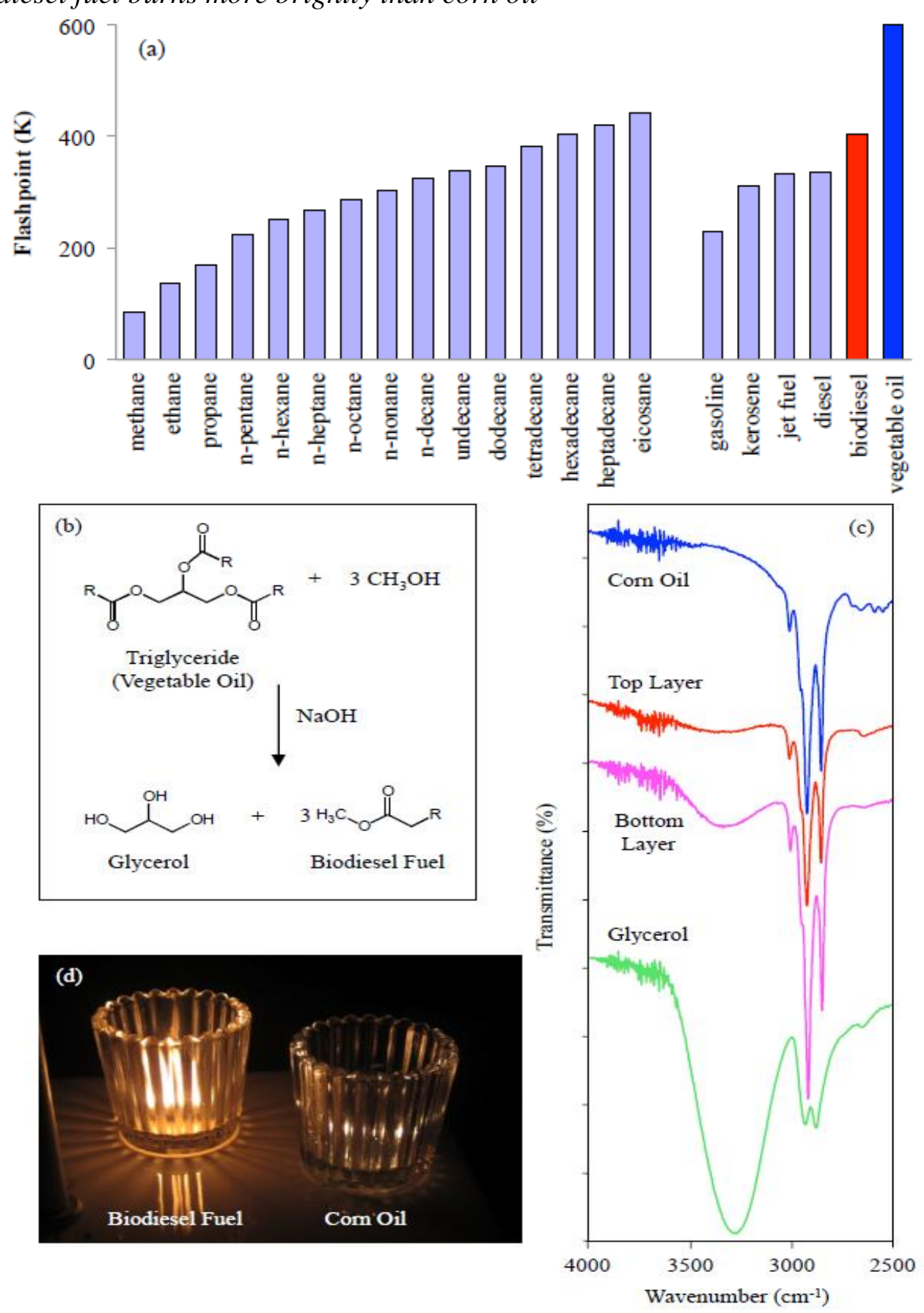
Thus, the conclusions from this experiment are that biodiesel fuels can be prepared readily by transesterification of waste cooking oils. Biodiesel fuels have a shorter hydrocarbon backbone and hence a lower flash point than the starting material. The Green principles highlighted in this experiment are: (i) the process uses renewable feedstocks and (ii) the products are biodegradable.

\section{Plastics and the Synthesis of Biodegradable Polymers}

Plastics play an important role in almost every aspect of our daily lives and it is, therefore, important to have an understanding of the chemical nature of these substances. Plastics can be robust and can persist in the environment long after they are discarded. Therefore, to prevent a build-up of plastics in landfills, it has become important to either recover waste plastic and recycle, or reprocess it as a different product. To help sort different plastics, a resin identification coding system was developed by the Society of the Plastics Industry (SPI) in 1988. The system uses numbers that are contained inside a triangle made of 3 arrows displayed in a clockwise fashion. The recycling numbers are arbitrary numbers that have no meaning other than the fact that they refer to different plastics. The following plastics can be identified by the SPI codes $1-6$, respectively: polyethylene terephthalate (PETE), high density polyethylene (HDPE), polyvinyl chloride (PVC), low density polyethylene (LDPE), polypropylene (PP), and polystyrene (PS). In addition, the SPI code 7 represents 'other' plastics, which include polycarbonate.

Household polymers with different resin identification codes can be analyzed by ATR FT-IR. Figure 5 shows representative IR spectra recorded of household polymers with SPI codes 1 - 6. It is, therefore, evident that IR spectroscopy can provide a useful means for students to identify plastics. However, while each polymer displays a characteristic IR spectrum, the spectra of HDPE and LDPE are similar. The similarity arises from the fact that they are both polyethylene, but one contains more branching (i.e. LDPE) than the other (i.e. HDPE).

While many of these plastics are safe, there is a concern with the use of polystyrene, because its precursor, styrene, has carcinogenic properties (Huff and Infante 2011). Another concern involves the plastic polycarbonate, which is a polyester made from a dihydric phenol (e.g. bisphenol A) and phosgene. Hydrolysis (i.e. degradation by water) of polycarbonates obtained from bisphenol A could lead to release of bisphenol A, a process known as leaching. Since bisphenol A mimics estrogen and is a known endocrine disruptor, a concern is that degradation of polycarbonates may interfere with many physiological pathways (Alonso-Magdalena et al. 2010). Thus, there is a need to replace some of these plastics with less harmful materials. In addition, a more desirable approach in Green Chemistry is to move away from using petroleum feedstocks (which are being rapidly depleted) to renewable feedstocks. Lactic acid (known as "milk acid") is derived biologically and is being used in large-scale industrial polymer production (Gross and Kalra 2002). Furthermore, lactic acid is biodegradable. 
Figure 5. ATR-IR Spectra. Household polymers with different resin identification codes

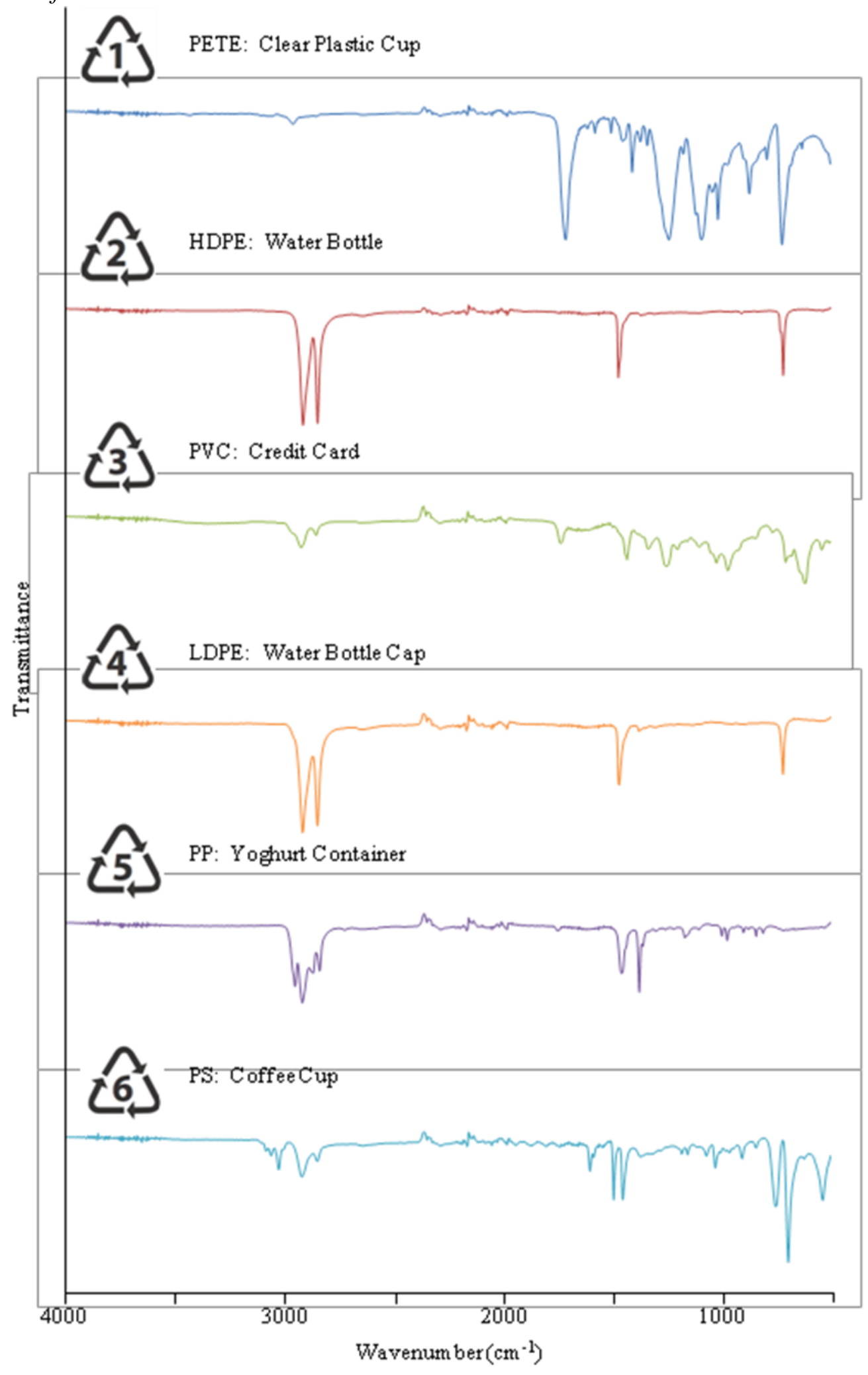


Polylactic acid (PLA) can be synthesized from lactic acid (Figure 6a). It is biodegradable over a period of 6 months to 2 years and, for this reason, is used in medical applications, such as pins, screws or mesh, which initially serve as a support, but eventually biodegrade to allow the organ or tissue to heal and eventually take over the load. The synthesis of PLA involves the use of benzyl alcohol, toluene and a catalyst (usually a tin compound) (Robert and Aubrecht 2008). Briefly, L-lactide (500 mg) was added to benzyl alcohol (0.070 M; 1.0 $\mathrm{mL})$ and tin(II)bis(2-ethylhexanoate) $(1.0 \mathrm{~mL})$ in toluene $(1.5 \mathrm{~mL})$ in a round bottom flask. The flask was attached to a condenser (through which air was blown) and the mixture was refluxed $\left(110^{\circ} \mathrm{C}\right)$. After one hour, the mixture was cooled, and quenched with $\mathrm{HCl}$ in $\mathrm{MeOH}(1 \mathrm{M} ; 0.20 \mathrm{~mL})$. The mixture was transferred to a beaker containing heptane $(200 \mathrm{~mL})$ and placed in an ice bath (20 min). After precipitation of the product, the heptane was carefully decanted. The precipitated polymer was characterized by ${ }^{1} \mathrm{H}$ NMR spectroscopy using a Bruker 500 AV III NMR spectrometer (Figure 6b) and also by ATR-IR spectroscopy (Figure 6c). The latter technique may be more accessible in an undergraduate laboratory.

Figure 6. Polylactide (PLA) Synthesis. (a) PLA production from L-lactic acid or lactide. (b) $1 H$ NMR spectra showing the methine proton in the lactide monomer (top panel) and in PLA (bottom panel) dissolved in CDCl3 (c) ATRIR spectra of L-lactide and PLA

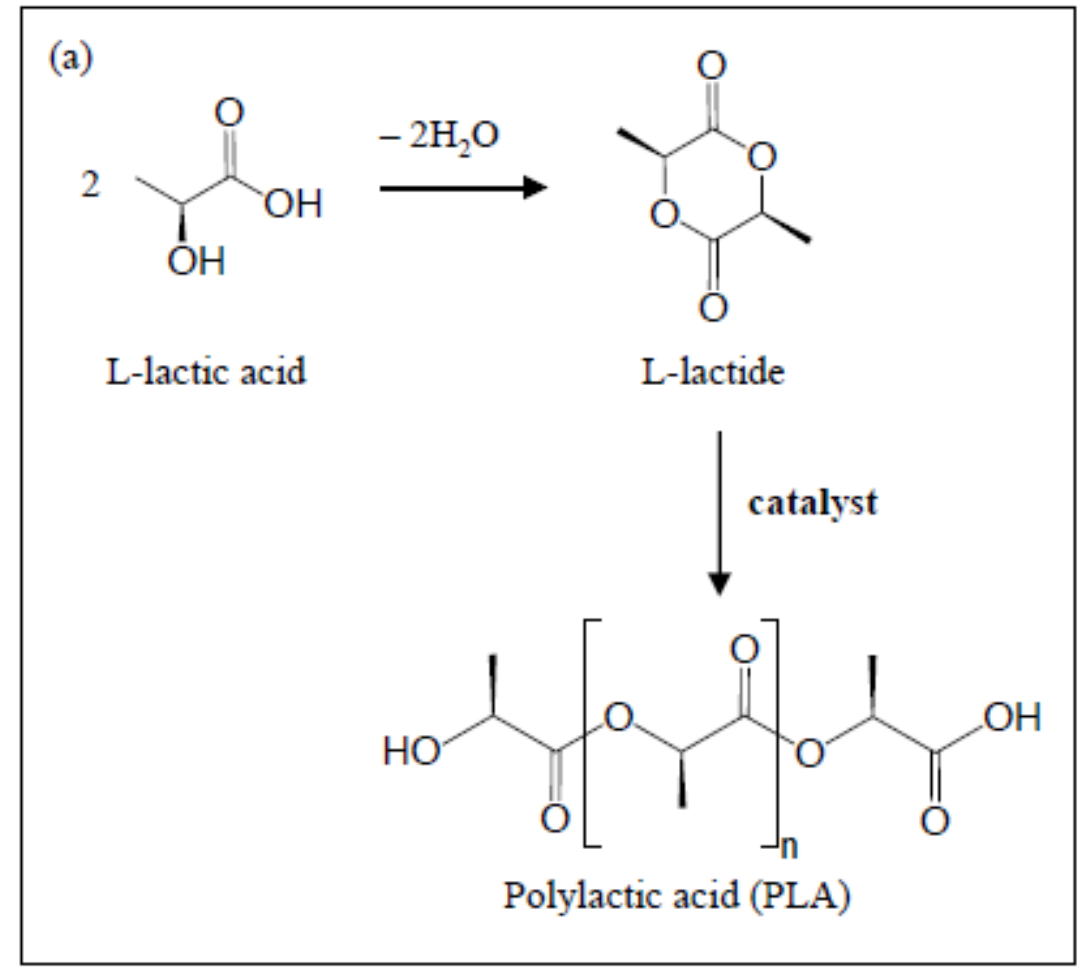


(b)
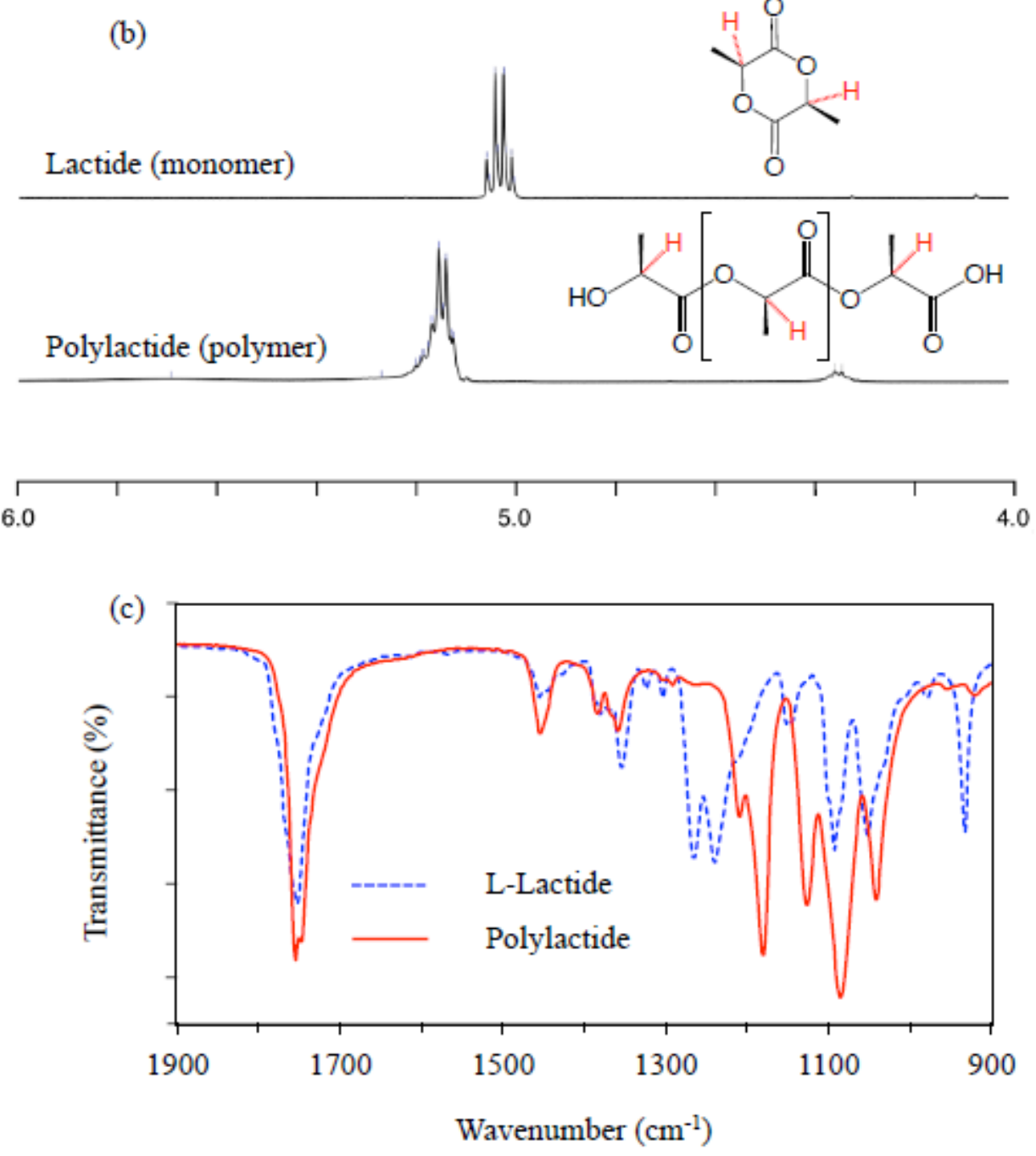

In conclusion, the student can learn that plastics and polymers can be easily characterized by IR spectroscopy. While the polylactide polymer is biodegradable, the tin catalyst is toxic (Wong et al. 2012), and thus, further research is required to identify a less toxic and more environmentally friendly catalyst. The Green principles that are featured here include: (i) high atom economy, (ii) the generation of a biodegradable product, (iii) the use of renewable feedstocks (i.e. production of PLA does not involve fossil fuels), and (iv) cradle-to-cradle recycling.

\section{Conclusion}

In summary, we have described how we tested and further designed three different types of experiment for implementation into an undergraduate Green Chemistry laboratory course. The three laboratory experiments involved (1) aspirin synthesis using microwave technology, (2) biodiesel fuel synthesis from oils used in the food industry, and (3) plastics and the synthesis of 
biodegradable polymers. In all cases, it was found that infra-red spectroscopy provided a standard method that could be applied to analyzing starting materials and products. The Green principles featured in these experiments, in total, concerned: (i) energy efficiency, (ii) safer chemicals and reaction media, (iii) less hazardous chemical synthesis, (iv) the use of renewable feedstocks, (v) the production of biodegradable products, (vi) high atom economy, and (vii) cradle-to-cradle recycling.

\section{Acknowledgments}

RKU would like to thank James Hutchison, Ken Doxsee and Julie Haack for conducting the workshop on Green Chemistry (sponsored by the National Science Foundation) at the University of Oregon (2011). RKU and TKB would like to thank Pace University for a Scholarly Research Award. The authors would also like to thank Julia Oktawiec for acquiring the ${ }^{1} \mathrm{H}$ NMR spectra of L-lactide and polylactide.

\section{References}

ACS. 2011. Laboratory Manual Chemistry in Context. McGraw-Hill, New York, NY. Alonso-Magdalena P, Ropero AB, Soriano S, Quesada I, Nadal A. 2010. Bisphenol-A: a new diabetogenic factor? Hormones (Athens) 9: 118-126.

Anastas PT, Warner JC. 1998. Green Chemistry: Theory and Practice. Oxford University Press, Oxford England; New York.

Anastas PT, Zimmerman JB. 2003. Design through the 12 principles of green engineering. Environ Sci Technol 37: 94A-101A.

Catoire L, Naudet V. 2004. A unique equation to estimate flash points of selected pure liquids application to the correction of probably erroneous flash point values. $J$ Phys Chem Ref Data 33: 1083-1111.

CEM. 2011. Microwave Chemistry: How it all Works. http://cem.com/page 130.html.

Doxsee KM, Hutchison JE. 2004. Green Organic Chemistry: Strategies, Tools, and Laboratory Experiments. Thomson-Brooks/Cole, Southbank, Vic., Australia; United States.

Gross RA, Kalra B. 2002. Biodegradable polymers for the environment. Science 297: 803-807.

Huff J, Infante PF. 2011. Styrene exposure and risk of cancer. Mutagenesis 26: 583584.

Jones MB. 2011. Laboratory Experiments for Organic Chemistry. Adams State College, personal communication.

Montes I, Sanabria D, Garcia M, Castro J, Fajardo J. 2006. A greener approach to aspirin synthesis using microwave irradiation. J Chem Educ 83: 628-631.

Pinzi S, Leiva D, Arzamendi G, Gandia LM, Dorado MP. 2011. Multiple response optimization of vegetable oils fatty acid composition to improve biodiesel physical properties. Bioresource Technol 102: 7280-7288.

Poliakoff M, Anastas P. 2001. A principled stance. Nature 413: 257.

Reid WV, Chen D, Goldfarb L, Hackmann H, Lee YT, Mokhele K, Ostrom E, Raivio K, Rockstrom J, Schellnhuber HJ et al. 2010. Environment and development. 
Earth system science for global sustainability: grand challenges. Science 330: 916917.

Robert JL, Aubrecht KB. 2008. Ring-opening polymerization of lactide to form a biodegradable polymer. $J$ Chem Educ 85: 258-260.

Rothamer DA, Donohue TJ. 2013. Chemistry and combustion of fit-for-purpose biofuels. Curr Opin Chem Biol. 17: 1-7.

Tang SY, Bourne RA, Poliakoff M, Smith RL. 2008. The 24 Principles of Green Engineering and Green Chemistry: "IMPROVEMENTS PRODUCTIVELY". Green Chem 10: 268-269.

Thompson JE. 2008. Biodiesel Synthesis. Greener Education Materials for Chemists, http://greenchem.uoregon.edu/Pages/ResultsAll.php.

Wong MH, Armour MA, Naidu R, Man M. 2012. Persistent toxic substances: sources, fates and effects. Rev Environ Health 27: 207-213. 
